\title{
MBCAST: A Forecast Model for Marssonina Blotch of Apple in Korea
}

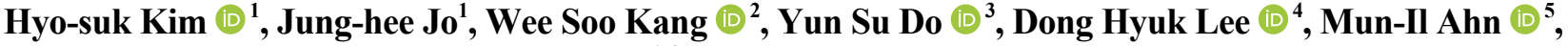 \\ Joo Hyeon Park (i) ${ }^{5}$, and Eun Woo Park (iD) 1,6,7* \\ ${ }^{I}$ Department of Agricultural Biotechnology, Seoul National University, Seoul 08826, Korea \\ ${ }^{2}$ Department of Agro-food Safety and Crop Protection, National Institute of Agricultural Sciences, Rural Development \\ Administration, Wanju 55365, Korea \\ ${ }^{3}$ Research Policy Bureau, Rural Development Administration, Jeonju 54875, Korea \\ ${ }^{4}$ Apple Research Institute, National Institute of Horticultural \& Herbal Science, Gunwi 39000, Korea \\ ${ }^{5}$ EPINET Corporation, Anyang 14056, Korea \\ ${ }^{6}$ Interdisciplinary Program in Agricultural and Forest Meteorology, Seoul National University, Seoul 08826, Korea \\ ${ }^{7}$ Research Institute of Agriculture and Life Sciences, Seoul National University, Seoul 08826, Korea
}

(Received on September 5, 2019; Revised on September 18, 2019; Accepted on September 19, 2019)

A disease forecast model for Marssonina blotch of apple was developed based on field observations on airborne spore catches, weather conditions, and disease incidence in 2013 and 2015. The model consisted of the airborne spore model (ASM) and the daily infection rate model (IRM). It was found that more than $\mathbf{8 0 \%}$ of airborne spore catches for the experiment period was made during the spore liberation period (SLP), which is the period of days of a rain event plus the fol-

\footnotetext{
*Corresponding author.

Phone) +82-2-880-4672, FAX) +82-2-872-2317

E-mail)ewpark@snu.ac.kr

ORCID

Hyo-suk Kim

https://orcid.org/0000-0002-3031-9333

Wee Soo Kang

https://orcid.org/0000-0001-9162-4086

Yun Su Do

https://orcid.org/0000-0003-0362-6706

Dong Hyuk Lee

https://orcid.org/0000-0003-4468-5964

Mun-Il Ahn

https://orcid.org/0000-0002-2240-1804

Joo Hyeon Park

https://orcid.org/0000-0001-6218-4456

Eun Woo Park

https://orcid.org/0000-0001-8305-5709

(c) This is an Open Access article distributed under the terms of the Creative Commons Attribution Non-Commercial License (http:// creativecommons.org/licenses/by-nc/4.0) which permits unrestricted noncommercial use, distribution, and reproduction in any medium, provided the original work is properly cited.
}

Articles can be freely viewed online at www.ppjonline.org. lowing 2 days. Of 13 rain-related weather variables, number of rainy days with rainfall $\geq 0.5 \mathrm{~mm}$ per day $\left(L_{d a y}\right)$, maximum hourly rainfall $\left(P_{\max }\right)$ and average daily maximum wind speed $\left(\boldsymbol{W}_{\text {avg }}\right)$ during a rain event were most appropriate in describing variations in airborne spore catches during $\operatorname{SLP}\left(S_{i}\right)$ in 2013. The ASM, $\hat{S}_{i}=30.280+5.860 \times L_{d a y} \times P_{\max }-2.123 \times \boldsymbol{L}_{d a y} \times \boldsymbol{P}_{\max } \times \boldsymbol{W}_{\text {avg }}$ was statistically significant and capable of predicting the amount of airborne spore catches during SLP in 2015. Assuming that airborne conidia liberated during SLP cause leaf infections resulting in symptom appearance after 21 days of incubation period, there was highly significant correlation between the estimated amount of airborne spore catches $\left(\hat{S}_{i}\right)$ and the daily infection rate $\left(R_{i}\right)$. The IRM, $\hat{R}_{i}=0.039+0.041 \times \hat{S}_{i}$, was statistically significant but was not able to predict the daily infection rate in 2015. No weather variables showed statistical significance in explaining variations of the daily infection rate in 2013.

Keywords : airborne spores, disease forecast model, Marssonina blotch of apple

Handling Editor : Park, Sook-Young

Marssonina blotch of apple (Malus domestica Borkh.) (MBA, hereafter), which is caused by Marssonina coronaria (Ellis \& J. J. Davis), is a devastating disease causing serious loss of apple yield in Korea (Kim et al., 1998; Lee et al., 2006). The disease distributed worldwide (Harada et 
al., 1974; Sagong et al., 2011; Tamietti and Matta, 2003). Symptoms of MBA appear on both leaves and fruits of infected trees. Leaf spots of dark brown color with 5-10 $\mathrm{mm}$ diameter appear on the surface of infected leaves and become irregular-shaped blotch. Infected leaves showing spots and blotch turn yellow and fall off from trees within 2-3 weeks after infection (Back and Jung, 2014). The premature defoliation due to severe infection impacts quality and yields of commercial apple products (Lee et al., 2012; Sharma et al., 2004; Takahashi et al., 1990). After defoliation of the infected leaves, $M$. coronaria overwinters on dead leaves and debris buried in soil or on the soil surface during the winter season, and recurrence of disease cycle begins in the following spring (Back and Jung, 2014). Ascospores of the fungus produced on apothecia are considered to be a source of the primary infection (Harada et al., 1974; Takahashi et al., 1990). In Korea, however, the sexual stage of $M$. coronaria has never been found yet and conidia of the fungus are known to cause the primary and secondary infections in apple orchards (Back and Jung, 2014). Primary infections by conidia generally occur on apple leaves from May to June followed by 2-6 weeks of incubation period before symptom appearance (Back and Jung, 2014). The incubation period may vary depending on orchard conditions. According to Lee et al. (2011), 4-yearold 'Fuji' apple seedlings showed tiny yellow spots on upper surface of leaves at 21 days after spray inoculation with conidial suspension of the fungus.

Occurrence of MBA varies from year to year, depending on availability of airborne conidia and weather conditions. It usually occurred under conditions of frequent rainfall and relatively low temperature during apple growing season (Back and Jung, 2014; Kim, 2004). The temperature range for mycelial growth and conidial production of $M$. coronaria was $5-30^{\circ} \mathrm{C}$ with the optimum at $20-25^{\circ} \mathrm{C}$ (Anil and Sharma, 2013; Zhao et al., 2010). In Korea, a severe epidemic of the disease was reported in 1993 when temperature was relatively low with prolonged rainy days during the summer season (Lee et al., 1993). Uhm (2010) reported that the disease occurred higher than $80 \%$ of apple orchards in Gyeongbuk province with 60 rainy days and cool temperature in summer in 1998 and 2003. Various weather factors such as rain and wind affect dispersal of airborne spores of plant pathogenic fungi (Legg and Powell, 1979; Willocquet et al., 1998). Previous researches suggested that spore liberation or removal from leaf surface is triggered by rain and wind speed (Hammett and Manners, 1974; Hirst and Stedman, 1963). Likewise, the effects of rain and wind are supposed to be important in spread of Marssonina blotch (McCartney, 1994). In Korea, Uhm (2010) noted that the first occurrence of MBA after overwintering became sooner due to earlier spore dispersal since late 2000s. Increase of disease incidence and relatively early spore dispersal have been reported in 2000s (Back and Jung, 2014; Park et al., 2013). However, quantitative relationships between weather factors on conidial dispersal of $M$. coronaria have not been elucidated yet.

Since the first report on MBA in Korea in 1916, the disease has been managed mainly by use of resistant cultivars and chemical sprays. Relatively resistant apple cultivars 'Fuji' and 'Hong-ro' have been introduced to replace susceptible cultivars 'Hong-ok' and 'Ralls Genet' since 1970s (Kim et al., 1998; Sagong et al., 2011). In addition, many studies on chemical control and fungicide spray programs against the disease have been reported (Back and Jung, 2014; Lee et al., 2009). Despite all the efforts to control MBA in Korea, the disease has increased since 1990s, causing substantial economic damage to apple growers due to early defoliation (Kim, 2004; Kim et al., 1998; Lee et al., 2006).

Apple growers in Korea were conventionally recommended 16 spays at 10 day intervals from late March to mid-September and efforts have been made to reduce the number of sprays by increasing the spray intervals from 10 to 15 days (Lee et al., 2008). The calendar-based fungicide application programs without considering weather conditions may result in practicing unnecessary sprays or missing necessary sprays. Consequently, disease forecasts on possible risks of MBA based on weather conditions would support apple growers in decision-making on fungicide sprays to control the disease. In China, a polynomial model was developed to estimate disease index using mean air temperature and relative humidity for 10 days ( $\mathrm{Li}$ et al., 2011). The research has identified the optimum conditions of MBA occurrence, which were $23^{\circ} \mathrm{C}$ and $90 \%$ relative humidity. However, Li et al. (2011) did not examine effects of airborne spores. Besides, the model validation was not performed based on additional data sets that were not used for the model development in their study.

The present study was conducted to determine weather variables that can be used to estimate the amount of airborne conidia of $M$. coronaria, and to develop a disease forecast model for MBA based on the amount of airborne conidia and weather conditions in apple orchards. The disease forecast model was named 'MBCAST' in this study.

\section{Materials and Methods}

Airborne spore catches and disease assessment. For 
development and evaluation of MBCAST, the amount of airborne spore catches and disease incidence data for 2 years were collected from field experiments conducted at apple orchards in the Gyeonggi-do Agricultural Research and Extension services, Hwasung, Korea in 2013 and in the Apple Research Institute of National Institute of Horticultural and Herbal Science, Gunwi, Korea in 2015. The two orchards are approximately $170 \mathrm{~km}$ apart. The data from 2013 were used to develop the model, and the model validation was conducted using the data from 2015.

The daily airborne conidia of $M$. coronaria were sampled by the Burkard 7-day Recording Volumetric Spore Sampler (Burkard Scientific Ltd., Uxbridge, UK). The spore sampler was installed in the middle of experimental plot and operated continuously from June 27 to October 8 in 2013 and from June 3 to October 21 in 2015. An air intake orifice of the sampler was located at $75 \mathrm{~cm}$ above ground and a flow rate was 101 per minute. The drum mounted with transparent plastic tape 'Melinex' (Burkard Scientific Ltd.) revolved constantly at a speed of $2 \mathrm{~mm}$ per hour. Airborne spores drawn through the orifice were impacted on adhesive coated tape with silicon grease. The drum with the tape was weekly replaced with new one and the tape was cut into seven daily segments at $48-\mathrm{mm}$ intervals. Each piece of the tape was placed on a microscope slide and airborne spores caught on the tape were counted under a light microscope (Leica DM2500, Leica Microsystems Gmbh, Wetzlar, Germany) at $400 \times$.

Assessment of disease incidence was carried out 13 times at 6-11 day intervals from August to October in 2013, and 20 times at 5-14 day intervals from June to October in 2015. Two branches from each of five selected 'Hongro' apple trees and eight branches from each of the 16 selected 'Fuji' apple trees were assessed in 2013 and 2015, respectively. Disease incidence was measured in terms of the percentage of diseased leaves in the total number of leaves on the branches surveyed.

Weather data. Weather data in 2013 and 2015 were obtained from the Gyeonggi-do Agricultural Research and Extension Services and the Korea Meteorological Administration, respectively. Automated weather stations (AWS) were located at about $1 \mathrm{~km}$ and $625 \mathrm{~m}$ distant from the experimental sites in 2013 and 2015, respectively. The AWS consisted of a data logger (CR10X, Campbell Scientific, Logan, UT, USA) with sensors to measure at $60 \mathrm{sec}$ intervals air temperature $\left({ }^{\circ} \mathrm{C}\right.$; HMP45C, Campbell Scientific), relative humidity (\%; HMP45C), rainfall (mm; TE525MM, Campbell Scientific), wind speed $(\mathrm{m} / \mathrm{s} ; 034 \mathrm{~A}$, Campbell Scientific), wind direction (degree, 034A, Campbell Scien-
Table 1. Weather factors during the period from the starting day of individual rain events until 2 days after the end of rain events

\begin{tabular}{ll}
\hline $\begin{array}{l}\text { Weather } \\
\text { variable }\end{array}$ & \multicolumn{1}{c}{ Description } \\
\hline$L_{\text {day }}($ day $)$ & Number of rainy days with rainfall $\geq 0.5 \mathrm{~mm} /$ day \\
$L_{\text {hour }}(\mathrm{h})$ & Duration in hours with rainfall $\geq 0.5 \mathrm{~mm} / \mathrm{h}$ \\
$P_{\max }(\mathrm{mm})$ & Maximum hourly rainfall \\
$P_{\text {sum }}(\mathrm{mm})$ & Total amount of rainfall \\
$H_{a v g}(\%)$ & Daily average relative humidity \\
$H_{\max }(\%)$ & Maximum hourly relative humidity \\
$H_{\min }(\%)$ & Minimum hourly relative humidity \\
$T_{\text {avg }}\left({ }^{\circ} \mathrm{C}\right)$ & Daily average air temperature \\
$T_{\max }\left({ }^{\circ} \mathrm{C}\right)$ & Maximum hourly temperature \\
$T_{\min }\left({ }^{\circ} \mathrm{C}\right)$ & Minimum hourly temperature \\
$W_{\text {avg }}(\mathrm{m} / \mathrm{s})$ & Average daily maximum wind speed \\
$W_{\max }(\mathrm{m} / \mathrm{s})$ & Maximum hourly wind speed \\
$W_{\min }(\mathrm{m} / \mathrm{s})$ & Minimum hourly wind speed \\
\hline
\end{tabular}

These factors were used as independent variables for model development and evaluation.

tific), and solar radiation (MJ $/ \mathrm{m}^{2}$; LI200X, Campbell Scientific). Hourly and daily weather data were generated and saved in the data logger.

Since liberation of fungal spores from inoculum sources are often associated with rain events (Aylor, 1975; Aylor et al., 1981; McCartney, 1994), 13 weather variables related with rain events in Table 1 were calculated for the period of individual rain events and the following 2 days after the end of individual rain events in 2013. It was found in this study that significant number of airborne conidia of $M$. coronaria were caught during the period from the starting day of individual rain events until 2 days after the end of rain events. Hereafter, this period is called 'the spore liberation period (SLP).' There were 15 rain events during the experiment period in 2013, and thus 15 data sets of 13 rainrelated weather variables were used for the model development. In 2015, there were 18 rain events and thus 18 data sets of weather data were used for the model validation.

Model development. MBCAST is a weather-driven disease forecast model that consists of an airborne spore model (ASM) and a daily infection rate model (IRM). Using weather data, ASM estimates the number of airborne spores caught during SLP of individual rain events $\left(S_{i}\right)$. The ASM-estimated airborne spore catches $\left(\hat{S}_{i}\right)$ were used by IRM to estimate daily infection rates of MBA. Both ASM and IRM are linear regression models developed based on the data in 2013.

The linear correlation analysis on the 13 rain-related weather variables in 2013 was conducted to examine 


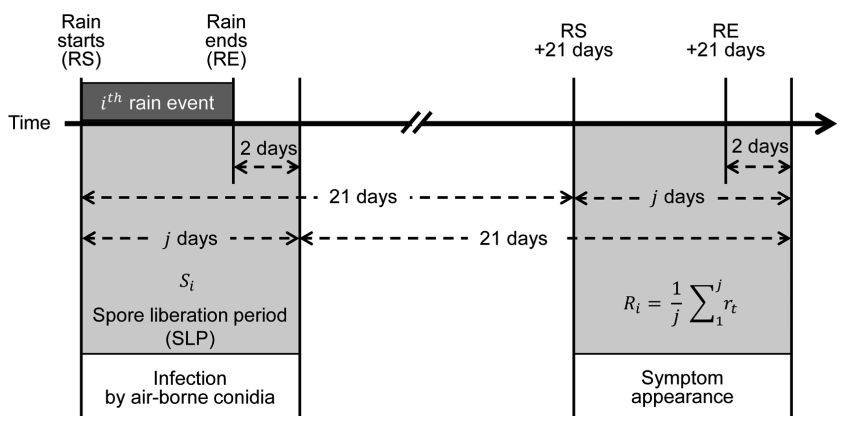

Fig. 1. Illustration on the relationship between the airborne spore catches $\left(S_{i}\right)$ liberated during the SLP of individual rain events and the mean daily infection rate $\left(R_{i}\right)$ that resulted from infection by airborne spores which had been liberated 21 days ago during SLP of the $i^{\text {th }}$ rain event. It was reported previously that the incubation period of Marssonina coronaria was 21 days or longer in apple orchards (Back and Jung, 2014; Lee et al., 2011). The daily infection rate $\left(r_{t}\right)$ was calculated from observed disease incidence data assuming that disease incidence increased at a rate of compound interest (Van der Plank, 1963).

collinearity among the variables. The stepwise regression analysis on the observed airborne spore catches $\left(S_{i}\right)$ was also carried out using the 13 rain-related weather variables as independent variables to select appropriate predictors that can be used in the ASM development. The appropriateness of predictors was evaluated based on the partial coefficient of determination $\left(R^{2}\right)$ of independent variables and the collinearity among the independent variables. Using the selected predictors, their quadratic, and two- and three-way interaction terms as independent variables, the stepwise regression analysis was applied to develop ASM. The forward selection of PROC STEPWISE of SAS version 9.4 (SAS Institute, Cary, NC, USA) was used with the criterion of $P \leq 0.15$ for entry of a variable into the model.

We assumed in this study that airborne spores liberated

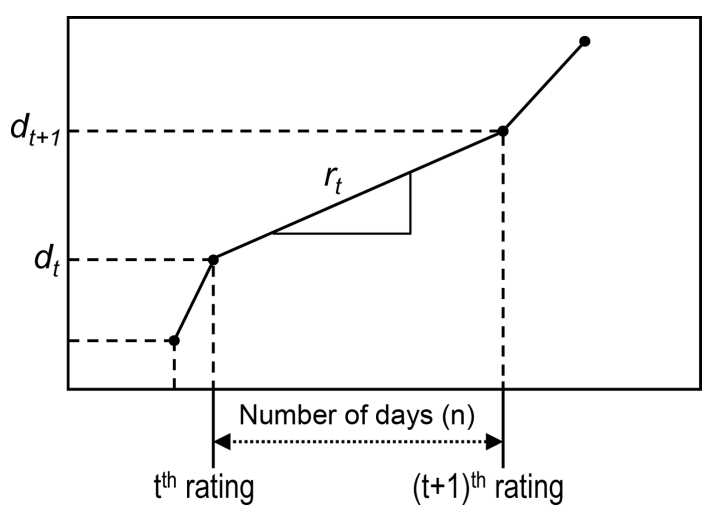

Fig. 2. A schematic plot of disease infection rate per day $\left(r_{t}\right)$. The $d_{t}(\%)$ is the disease incidence assessed at $t^{\text {th }}$ rating. during SLP caused leaf infections resulting in symptom appearance after 21 days of incubation period. Lee et al. (2011) reported that the incubation period of $M$. coronaria was 21 days in apple orchards. Fig. 1 illustrates the relationship between the airborne spore catches for $i^{\text {th }}$ rain event $\left(S_{i}\right)$ and the corresponding daily infection rate after the incubation period of 21 days $\left(R_{i}\right)$. In this study, $R_{i}$ was supposed to be the mean daily infection rate at which disease incidence increased due to infections by airborne conidia liberated during SLP for $i^{\text {th }}$ rain event. Consequently, $R_{i}$ was the mean daily infection rate that occurs at 21 days after the $i^{t h}$ rain event. The $R_{i}$ was calculated from the apparent infection rate $\left(r_{t}\right)$ that was obtained from observed disease incidence. The apparent infection rate $\left(r_{t}\right)$, which was illustrated schematically in Fig. 2, was calculated from observed disease incidence data using the compound interest formula as the following equation:

$$
r_{t}(\%)=\left[\left(\frac{d_{t+1}}{d_{t}}\right)^{\frac{1}{n_{t}}}-1\right] \times 100
$$

, where $d_{t}(\%)$ is the disease incidence measured at the $t^{\text {th }}$ disease observation and $n_{t}$ is the number of days between the $t^{\text {th }}$ and $(t+1)^{t h}$ disease observations. It was assumed that disease incidence increased at a rate of compound interest as suggested by Van der Plank (1963) and disease incidence increased at a constant rate between two disease observations. For $S_{i}$, the corresponding $R_{i}$ was calculated as follows:

$$
R_{i}=\frac{1}{j} \Sigma_{1}^{j} r_{t}
$$

, where $j$ is the number of days during SLP of the $i^{\text {th }}$ rain event (Fig. 1).

We wanted to develop an IRM to predict $R_{i}$ based on airborne spore catches $\left(\hat{S}_{i}\right)$ and weather data for 23 days from the next day after a rain event. In order to select a time-window containing most appropriate weather variables that could explain variations of $R_{i}, 23$ data sets were prepared for 23 time-window widths of $1,2,3, \ldots$, and 23 days after the end of $i^{\text {th }}$ rain event. The stepwise regression analysis for each of the 23 data sets was conducted on the observed $R_{i}$ using $\hat{S}_{i}$ and the 13 weather variables in Table 1 as independent variables. The forward selection of PROC STEPWISE of SAS version 9.4 (SAS Institute) was used with the criterion of $P \leq 0.15$ for entry of a variable into the model. The final candidate of IRM was selected based on the partial $R^{2}$ and collinearity among the predictors used in the models. The variance inflation factors (VIFs) and the condition index $(\mathrm{CI})$ were used to detect collinearity among 
predictors in the models. The PROC REG of SAS version 9.4 (SAS Institute) was applied to generate VIFs and CI among predictors of candidate models.

Model validation. Performance of ASM and IRM was evaluated using the data from 2015, which included airborne spore catches, observed disease incidence, and hourly weather data. The ASM-estimated airborne spore catches $\left(\hat{S}_{i}\right)$ and the IRM-estimated daily infection rate $\left(\hat{R}_{i}\right)$ for individual rain events in 2015 were compared with the observed airborne spore catches $\left(S_{i}\right)$ and the observed daily infection rate $\left(R_{i}\right)$, respectively, using the paired $t$-test. The null hypothesis for the paired $t$-test assumed that the true mean difference between the estimated and observed data corresponding to individual rain events was zero. The normality in frequency of the differences was also evaluated using the Shapiro-Wilk test to confirm appropriateness of the paired $t$-test. Outliers in the airborne spore catches and daily infection rate data were excluded for the Shapiro-Wilk test because outliers could bias the results of paired $t$-test (Kwak and Kim, 2017). Excluding two outliers on both extremes of data sets, 16 and 11 pairs of data were used in the evaluation of ASM and IRM, respectively. The PROC UNIVARIATE of SAS version 9.4 (SAS Institute Inc.) was applied for the paired $t$-test and the Shapiro-Wilk test.

\section{Results}

Airborne spore catches in relation to rain events. The number of daily airborne spore catches and periods of rain events in both years are presented in Fig. 3. The discrete number of rain events during the study periods were 16 and 23 times in 2013 and 2015, respectively. There were 1 to 11 days of intermittent dry periods without rainfall between two consecutive rain events. Most of rain events were 1 or 2 days long with the longest of 9 days on 10-18 July 2013 and four days on 6-9 July 2015. Throughout the study peri-
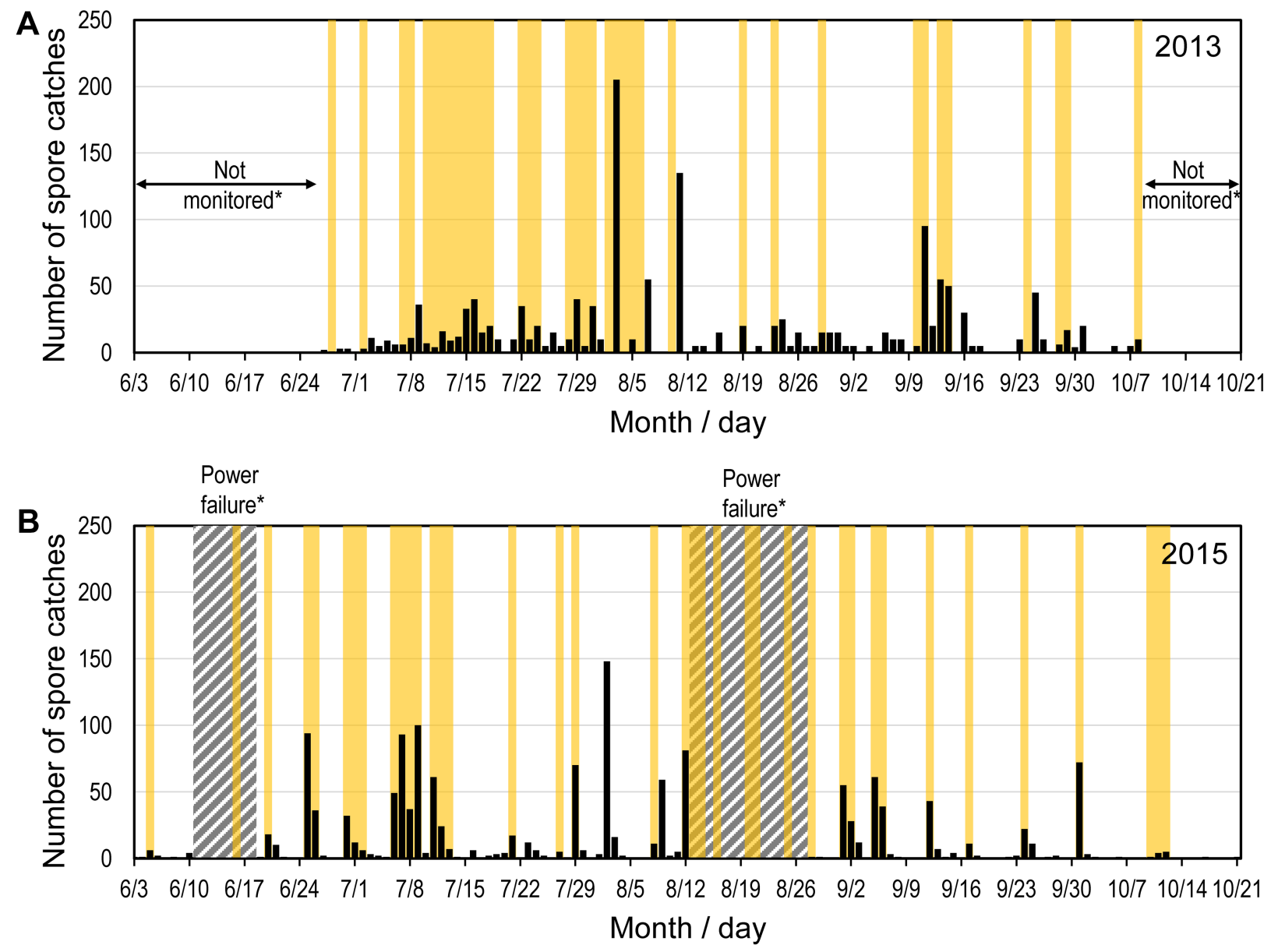

Fig. 3. Rainfall periods (yellow area) and daily airborne spore catches (black histogram) from June 27 to October 10,2013 at Hwaseong

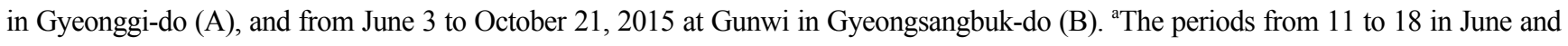
from 13 to 27 in August in 2015 were excluded due to the power failure of the Burkard spore sampler. 
A

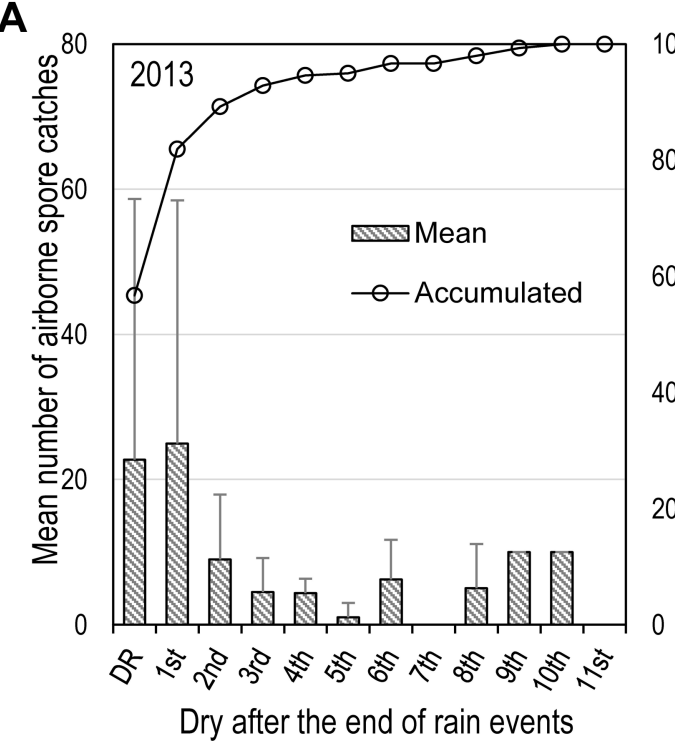

B

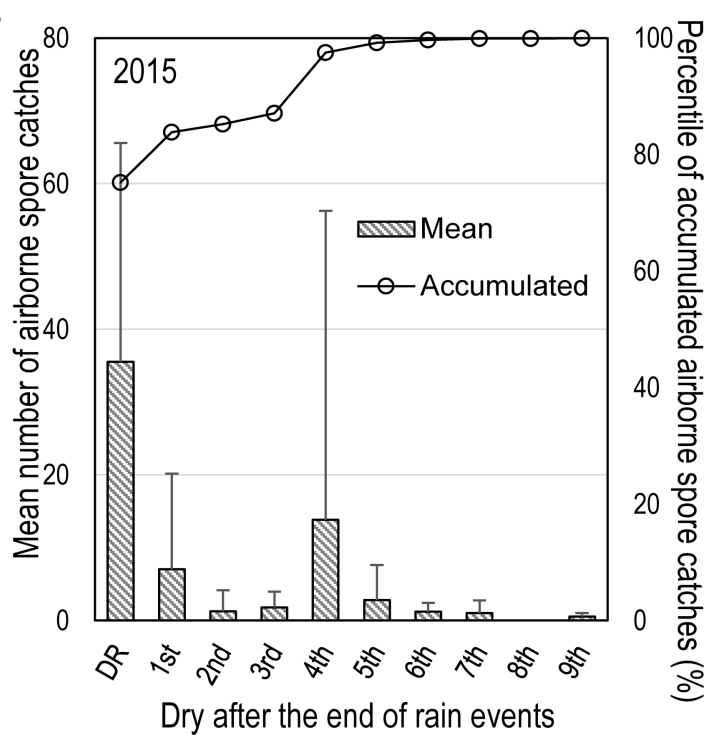

Fig. 4. The mean and percentile of accumulated airborne spore catches during days of rain events (DR) and the following dry days without rainfall of $0.5 \mathrm{~mm}$ after the end of individual rain events in 2013 (A) and 2015 (B). The periods of power failure in 2015 were excluded in the calculation.

od in 2013 , there were $159 \mathrm{~h}$ of rainfall in 37 rainy days. It was $173 \mathrm{~h}$ of rainfall in 38 rainy days in 2015 . The average rainfall hours per rainy day were 4.3 and $4.6 \mathrm{~h}$ in 2013 and 2015, respectively.

Airborne spores were caught starting from June in both years although only a few spores were trapped in June. The number of airborne spore catches per day varied especially during the days with rainfall and the next day after rain events (Fig. 4). It was found that $89.2 \%$ and $85.2 \%$ of the total airborne spore catches were made during SLP, which was the period from the starting day of individual rain events until 2 days after the end of rain events, in 2013 and 2015 , respectively. From the third day after the end of individual rain events, no or small number of airborne spores were caught a day in most cases except for 2 August 2015 when 148 spores were caught. The extraordinary spore

Table 2. Weather variables selected to explain variations in the number of airborne spore catches in 2013

\begin{tabular}{lccccc}
\hline Variable & $b$ & Std. error & $R^{2}$ & $F$ & $P$-value \\
\hline Intercept & 59.390 & 37.376 & - & 2.52 & 0.1404 \\
$L_{\text {day }}$ & 17.984 & 5.545 & 0.380 & 10.52 & 0.0078 \\
$P_{\text {max }}$ & 4.217 & 1.440 & 0.217 & 8.57 & 0.0137 \\
$W_{\text {avg }}$ & -34.062 & 17.765 & 0.101 & 3.68 & 0.0815 \\
Model & - & - & 0.698 & 8.45 & 0.0034 \\
\hline
\end{tabular}

Stepwise regression analysis was applied using all weather variables listed in Table 1. The forward selection of PROC STEPWISE of SAS was used with the criterion of $P \leq 0.15$ for entry of a variable into the model. catches resulted in the high variation on the fourth day after rain events in 2015 (Fig. 4).

Airborne spore model (ASM). Of the 13 rain-related weather variables in Table $1, L_{\text {day }}, P_{\max }$, and $W_{\text {avg }}$ were found to be most appropriate candidates that could describe variations in daily airborne spore catches during SLP in 2013 (Table 2). The partial $R^{2}$ of linear model indicated that $38.0 \%, 21.7 \%$, and $10.1 \%$ of the daily variations of airborne spore catches were accounted for by $L_{d a y}, P_{\max }$, and $W_{\text {avg }}$, respectively. No other variables were selected

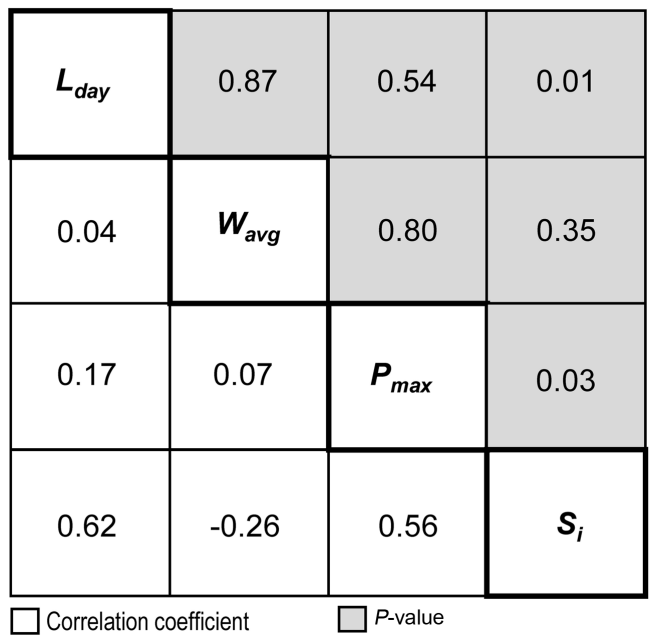

Fig. 5. Correlation matrix of observed airborne spore catches $\left(S_{i}\right)$ and the weather variables in 2013, which were selected for airborne spore model development. 
Table 3. The airborne spore model (ASM) selected by stepwise regression analysis to esitmate airborne spore catches during the spore liberation period $^{\mathrm{a}}$

\begin{tabular}{lccccc}
\hline Variable & $b$ & Std. error & $R^{2}$ & $F$ & $P$-value \\
\hline Intercept & 30.280 & 9.227 & - & 10.77 & 0.0066 \\
$L_{d a y} \times P_{\max }$ & 5.860 & 0.747 & 0.610 & 61.56 & $<0.001$ \\
$L_{d a y} \times P_{\max } \times W_{\text {avg }}$ & -2.123 & 0.370 & 0.286 & 32.93 & $<0.001$ \\
Model & - & - & 0.896 & 8.45 & $<0.001$ \\
\hline
\end{tabular}

${ }^{a}$ The forward selection of PROC STEPWISE of SAS was used with the criterion of $P \leq 0.15$ for entry of a variable into the model.

based on the criterion of $P \leq 0.15$ for entry of a variable into the model. The correlation matrix in Fig. 5 showed no significant linear correlations among $L_{d a y}, P_{\max }$, and $W_{\text {avg }}$, indicating that autocorrelation among the weather variables was negligible in the model. The $L_{d a y}$ and $P_{\max }$ showed statistically significant correlations at $P=0.15$ with observed $S_{i}$ whereas $W_{\text {avg }}$ did not.
The stepwise regression analysis on observed $S_{i}$ in 2013 resulted in a multiple regression model in Table 3. Of the 19 independent variables which were included in the stepwise regression analysis, $L_{d a y} \times P_{\max }$ and $L_{d a y} \times P_{\max }$ $\times W_{\text {avg }}$ were selected. No other variables had statistically significant coefficients at $P=0.001$. The model was able to explain $89.6 \%$ of the total variations of daily airborne spore catches, of which $61.0 \%$ and $28.6 \%$ was accounted for by the two-way interaction between $L_{d a y}$ and $P_{\max }$, and the three-way interaction among $L_{d a y}, P_{\max }$, and $W_{\text {avg }}$, respectively. Based on this result, the following equation was determined as the ASM to estimate daily airborne spore catches:

$$
\begin{aligned}
\hat{S}_{i}= & 30.280+5.860 \times L_{d a y} \times P_{\max }-2.123 \times L_{\text {day }} \times P_{\max } \\
& \times W_{\text {avg }}
\end{aligned}
$$

For $L_{d a y}$ varying from 1 to 9 days, Eq. (3) was plotted in Fig. 6. It was noticed that airborne spore catches increased
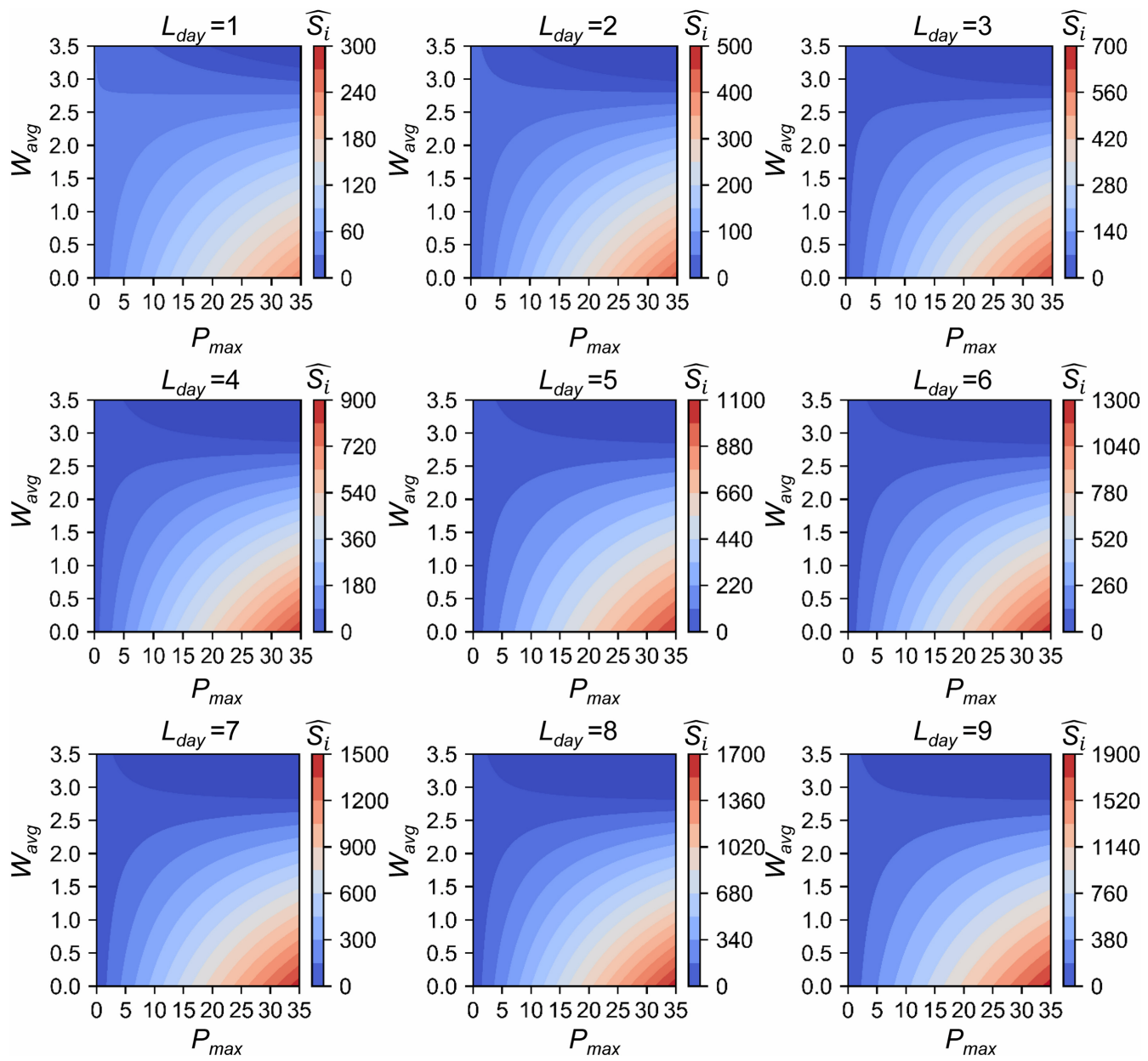

Fig. 6. Changes in amount of estimated airborne spore catches $\left(\hat{S}_{i}\right)$ affected by $L_{d a y}, P_{\text {max }}$ and $W_{\text {avg }}$. The $\hat{S}_{i}$ is the number of airborne spore catches during spore liberation period, which is the days of rain event plus the following 2 days after the end of rain event. Note the difference in scales of the number of spores for different $L_{d a y}$. 

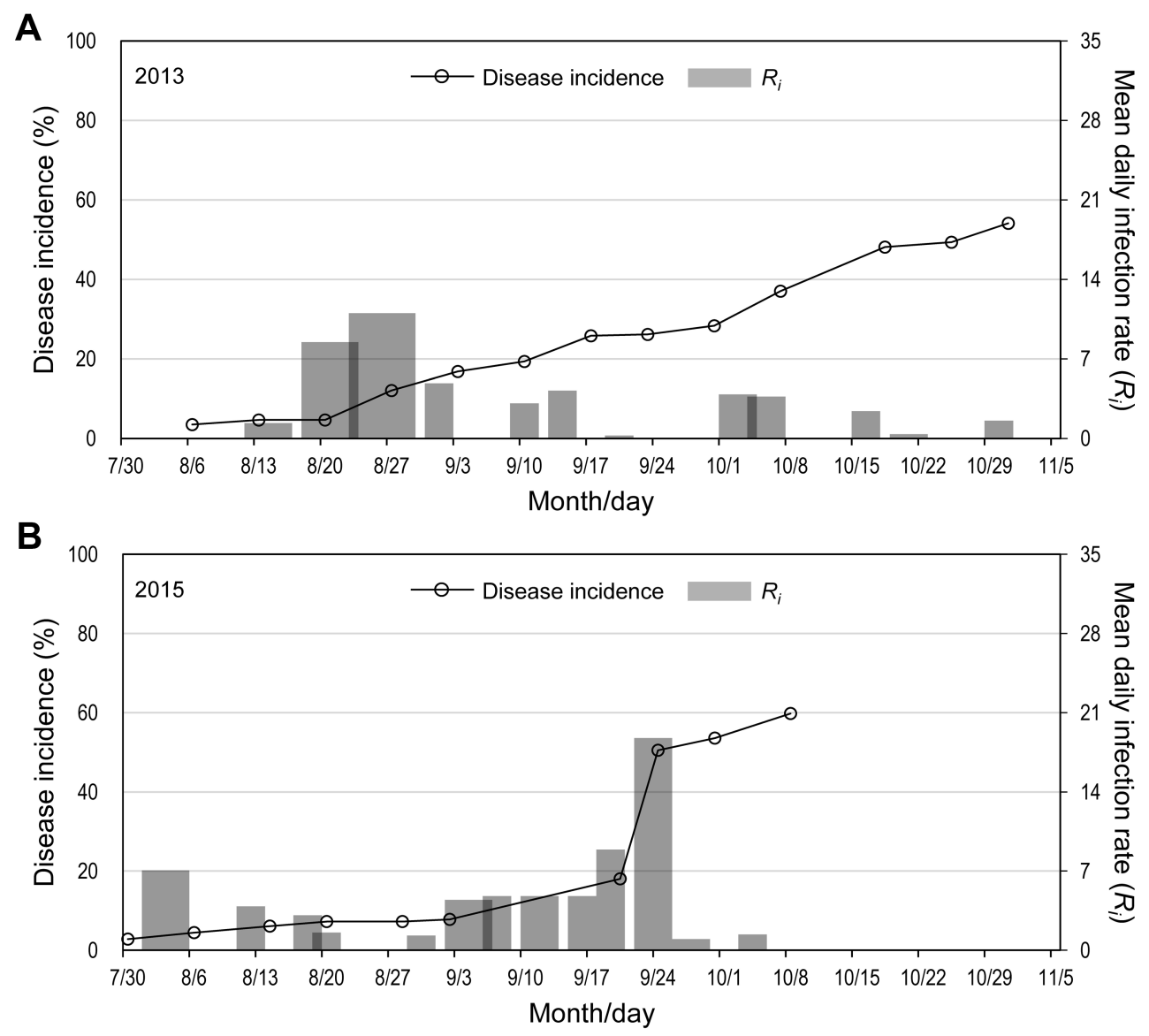

Fig. 7. Disease progress curves of Marssonina blotch of apple along with the mean daily infection rate $\left(R_{i}\right)$ that occurred during the period of 21 days after individual rain events in 2013 (A) and 2015 (B).

as $P_{\max }$ increased and $W_{\text {avg }}$ decreased. In addition, the longer rainy days continued, the more airborne spores were caught during SLP.

Disease progress and the infection rate $\left(\boldsymbol{R}_{i}\right)$. The disease progress curves of MBA in 2013 and 2015 were presented in Fig. 7 along with the daily infection rates $\left(R_{i}\right)$ that occurred at 21 days after SLP of the $i^{\text {th }}$ rain event. In 2013, the disease was first observed in early August and increase in disease incidence was noticed from late August, after which disease incidence increased apparently at relatively constant rates until the end of season. In 2015, however, slow increase in disease incidence occurred from the start of disease development in late July, which was followed by a sudden increase from mid-September. The final disease incidence was similar in both years although the shapes of disease progress curves were different. The daily infection rates $\left(R_{i}\right)$ in Fig. 7 described appropriately the changes in disease incidence over time in both years. The overlapped $R_{i}$ were due to only one dry day without rainfall between two consecutive rain events. There were two cases in both
Table 4. The infection rate model resulted from stepwise regression analysis on observed daily infection rate at 21 days after individual rain events ${ }^{\mathrm{a}}$

\begin{tabular}{lccccc}
\hline Variable & $b$ & Std. error & $R^{2}$ & $F$ & $P$-value \\
\hline Intercept & 0.039 & 0.757 & - & 0.00 & 0.9604 \\
$\hat{S}_{i}$ & 0.041 & 0.007 & 0.788 & 37.13 & $<0.001$ \\
Model & - & - & 0.788 & 37.13 & $<0.001$ \\
\hline
\end{tabular}

The stepwise regression analysis was conducted for each of 23 data sets representing conduciveness of weather conditions during 1, 2, 3, $\cdots$, and 23 days after the end of rainfall. All weather variables were not selected based on statistical significance of parameter estimates $(P \leq 0.05)$ and collinearity among independent variables measured in terms of the variance inflation factors $(\leq 2)$ and the condition index $(\leq 10)$. The forward selection of PROC STEPWISE of SAS was used with the criterion of $P \leq 0.15$ for entry of a variable into the model.

years that two consecutive rain events were separated by one day of intermittent dry period without rainfall.

The infection rate model (IRM). The stepwise regression analysis on $R_{i}$ resulted in a simple regression model with $\hat{S}_{i}$ 


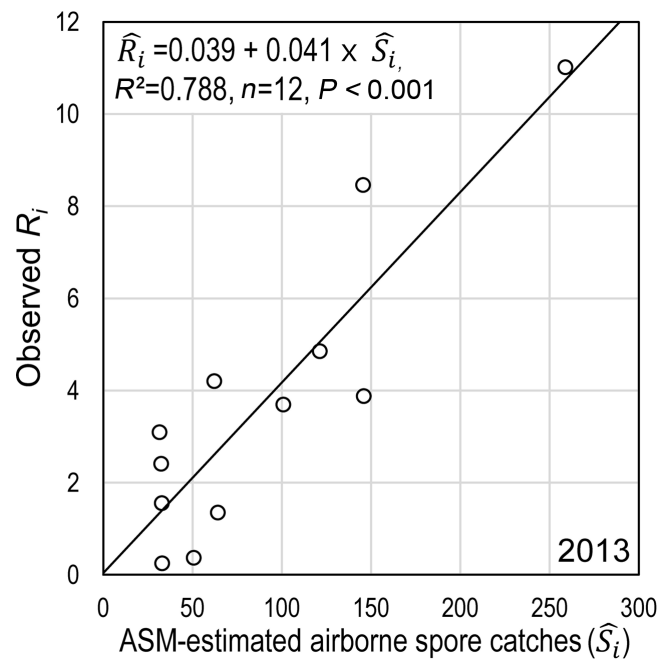

Fig. 8. Relationship between the airborne spore model (ASM)estimated airborne spore catches $\left(\hat{S}_{i}\right)$ and the mean daily infection rate $\left(R_{i}\right)$ calculated from the observed disease incidence in 2013.

as independent variable (Table 4), where $\hat{S}_{i}$ was the ASMestimated airborne spore catches during SLP of the $i^{\text {th }}$ rain event. For all 23 data sets for 23 time-window widths of 1, 2, $3, \ldots$, and 23 days after the end of $i^{\text {th }}$ rain event, only $\hat{S}_{i}$ was selected at the first step of analysis and its coefficient was statistically significant at $P=0.001$. Coefficients of any weather variables representing conduciveness of weather conditions during the following $1,2,3, \ldots, 23$ days after individual rain events were not statistically significant at $P=$ 0.05 . The $R^{2}$ of the model indicated that $78.8 \%$ of the total variation of $R_{i}$ was accounted for by $\hat{S}_{i}$. Consequently, the following equation was selected as IRM:

$$
\hat{R}_{i}=0.039+0.041 \times \hat{S}_{i}
$$

, where $\hat{R}_{i}$ is the estimated mean daily infection rate at 21 days after infections by airborne conidia liberated during SLP of the $i^{\text {th }}$ rain event, $\hat{S}_{i}$ is the ASM-estimated airborne spore catches during SLP of the $i^{\text {th }}$ rain event. The relationship between $\hat{S}_{i}$ and $R_{i}$ was plotted in Fig. 8 .

Model validation. The $t$-test on the differences between 16 pairs of $\hat{S}_{i}$ and $S_{i}$ in 2015 resulted in the $P$-value of 0.276 , indicating that the null hypothesis could not be rejected at the significance level of $P=0.05$. The Shapiro-Wilk test suggested that the frequency distribution of differences between $\hat{S}_{i}$ and $S_{i}$ was normally distributed $(P=0.912)$. Therefore, the paired $t$-test was valid and it could be concluded that ASM was capable of predicting airborne spore catches in 2015 using $L_{d a y}, P_{\max }$, and $W_{\text {avg. }}$. However, there was a large variation in the observed airborne spore

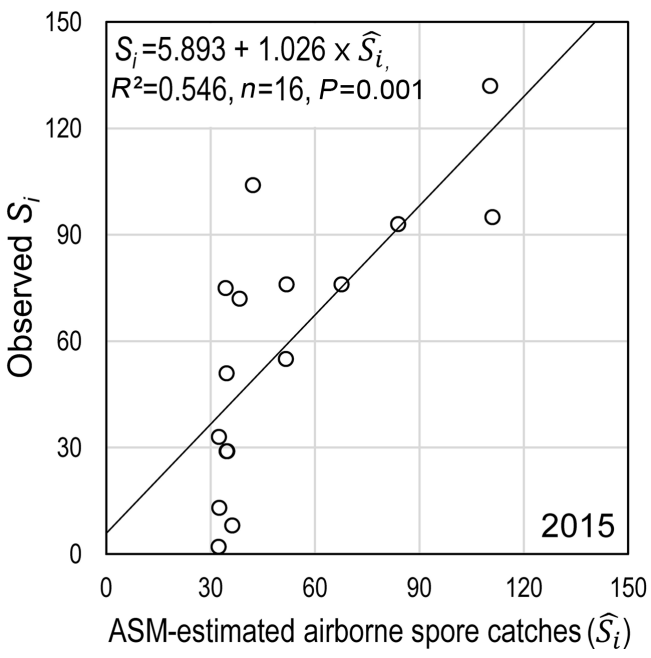

Fig. 9. Relationship between the airborne spore model (ASM)estimated $\left(\hat{S}_{i}\right)$ and the observed $\left(S_{i}\right)$ airborne spore catches in 2015.

catches $\left(S_{i}\right)$, when the ASM-estimated $\left(\hat{S}_{i}\right)$ was relatively small (Fig. 9).

In the case of the differences between 11 pairs of $\hat{R}_{i}$ and $R_{i}$, the paired $t$-test and the Shapiro-Wilk test resulted in statistical significance at $P=0.007$ and $P=0.243$, respectively. This result suggested that the frequency distribution of differences between $\hat{R}_{i}$ and $R_{i}$, was normally distributed and the null hypothesis that the mean difference was zero was rejected at $P=0.05$. Consequently, it could be concluded that the paired $t$-test was valid and IRM was not good enough to predict daily infection rate at 21 days after infections by airborne conidia liberated during SLP of a rain event in 2015 .

\section{Discussion}

MBCAST consists of two sub-models, ASM and IRM, to estimate airborne spore catches and daily infection rate, respectively, of Marssonina blotch on apple. Both ASM and IRM were developed based on the field observations on airborne spore catches, weather conditions, and disease incidence. The MBCAST uses three weather variables, i.e., $L_{d a y}, P_{\max }$, and $W_{\text {avg }}$ as input variables. All of the weather variables are rain-related factors, which are known to affect fungal spore liberation and deposition (Aylor et al., 1981; Davis, 1987; Hammett and Manners, 1974; Hirst and Stedman, 1963; Willocquet and Clerjeau, 1998). Although MBCAST is a weather-driven model, it is different from other weather-driven infection period models which determines possible success or failure of infection by airborne pathogens. In general, infection period models for foliar diseases 
were developed empirically based on artificial inoculation studies under controlled temperature and wetness period or relative humidity conditions (Anil and Sharma, 2013; Li et al., 2011; Magarey et al., 2005; Sastrahidayat and Nirwanto, 2016; Sharma et al., 2009; Zhao et al., 2010).

Previous studies in Korea showed that airborne spores of $M$. coronaria were trapped as early as in April, and the first occurrence of MBA after overwintering was often observed in May and June (Do and Park, 2015). In this study, airborne conidia of $M$. coronaria were trapped from June and the disease symptoms on leaves were first found in the experimental orchards in August and July in 2013 and 2015, respectively (Figs. 3 and 7). The late inception of disease development was probably due to the late dispersal of airborne conidia in the orchards. However, the late installation of spore trap in this study may have missed airborne spores early in the seasons.

Coincidence of airborne spore catches and rain events in both years (Fig. 3) suggested that liberation of airborne spores was triggered by rain events. The number of airborne spore catches tapered off as dry days continued after rain events. However, the abundant airborne spore catches on 2 August 2015 were exceptional. We could not find extraordinary weather factors that may have affected air spore concentration on that day. However, Gottwald and Bertrand (1982) noticed, in the case of Fusicladium effusum (pecan scab), a dramatic increase in hourly spore concentration in the air when leaf wetness decreased abruptly at sunrise on days with no rain. Unfortunately, wetness data were not available in 2015 in this study. Association of airborne spore dispersal with rain events has been intensively studied previously (Kurkela, 1997; McCartney and Bainbridge, 1984; Penet et al., 2014; Sache, 2000; Xu et al., 1995).

According to ASM, airborne spore concentration of $M$. coronaria was influenced by the number of rainy days with rainfall of $\geq 0.5 \mathrm{~mm} /$ day $\left(L_{d a y}\right)$, the maximum hourly rainfall $\left(P_{\max }\right)$, and the average hourly wind speed $\left(W_{\text {avg }}\right)$ during rain events. The correlation matrix in Fig. 5 indicated that the three rain-related weather variables were independent of each other. Consequently, the two-way interaction of $L_{d a y}$ and $P_{\max }$ and the three-way interaction of $L_{d a y}$ and $P_{\max }$ and $W_{\text {avg }}$ in Eq. (3) would not have collinearity between them. Collinearity between independent variables in regression analysis undermines the statistical significance of independent variables (Allen, 1997). Unlike $L_{d a y}$ and $P_{\max }, W_{\text {avg }}$ did not have significant correlation with the airborne spore catches $\left(S_{i}\right)$ at $P=0.05$. However, $W_{\text {avg }}$ was included in ASM because effects of wind speed on fungal spore dispersal were well established in the literature (Aylor,
1975; Aylor et al., 1981; Hammett and Manners, 1974; Legg and Powell, 1979; McCartney, 1994).

Clear explanation on impacts of the three weather variables on airborne spore concentration may not be possible because of the variation in weather and the complex interactions among weather factors. However, ASM suggested positive effects of $L_{d a y}$ and $P_{\max }$, and a negative effect $W_{\text {avg }}$ on airborne spore concentration. According to Gottwald and Bertrand (1982), airborne spore catches increased immediately following light rain showers and during prolonged intermittent rainy periods although rainfall caused immediate decrease in airborne spore concentration. More conidia must have liberated from leaf surface after rain showers as $L_{d a y}$ increased. In this study, rainfall of $\geq 5 \mathrm{~mm} /$ day occurred for less than $5 \mathrm{~h}$ per rainy day at the average, indicating that there were prolonged post-rainfall periods favorable for spore liberation during rainy days. In the case of $P_{\max }$, it may have affected positively spore production from lesions on leaves, and negatively spore concentration in the air. It is known that rainfall affects spore dispersal in three ways: (1) by providing moisture for mycelial growth and spore production, (2) as a force releasing conidia from the conidiophores, and (3) by washing-off spores in the air and on the surface of leaves (Burch and Levetin, 2002; Fitt et al., 1989; Kurkela, 1997; Oliveira et al., 2009; Troutt and Levetin, 2001; Willocquet and Clerjeau, 1998). As for $W_{\text {avg }}$, airborne spores were probably blown away by wind. Wind and gust showed negative correlation with airborne spore concentrations of different fungi (Quintero et al., 2010).

With regard to the IRM, three assumptions were made in this study: (1) disease incidence of MBA, which is measured in terms of the percentage of diseased leaves, increases at a rate of compound interest; (2) the apparent infection rate $\left(r_{t}\right)$ is constant between two consecutive disease observation dates; and (3) it takes 3 weeks of incubation period to develop symptoms on leaves after infection by airborne conidia. The first assumption was based on the proposal by Van der Plank (1963) that pathogens of 'compound interest diseases' multiply through successive generations in the course of an epidemic. $M$. coronaria produces airborne conidia to cause successive infections and daughter lesions on a same apple plant, which is multiplication in a form similar to compound interest as suggested by Van der Plank (1963). Although the apparent infection rate of MBA should vary depending on various environmental and host factors under field conditions, we considered the apparent infection rate to be constant for the sake of simplicity. With the second assumption on constant apparent infection rate, we were 
able to focus the relationship between the amount of airborne spores $\left(S_{i}\right)$ released during a SLP of a rain event and the average daily infection rate $\left(R_{i}\right)$ that was caused by $S_{i}$ at 21 days after SLP of a rain event (Fig. 1). The incubation period of $M$. coronaria is known to be 2-6 weeks depending on weather conditions in Korea (Back and Jung, 2014). According to Lee et al. (2011), tiny yellow spots appeared on upper surface of leaves after 21 days in the field since 4-year-old 'Fuji' apple trees were spray-inoculated with conidial suspension of the fungus. They found typical MBA symptoms at 40-45 days after inoculation in the field. Based on the information in the literature, we employed the incubation period of 3 weeks in the process of MBCAST development (Fig. 1). The statistical significance $(P<0.001)$ and $R^{2}=0.788$ of IRM in Table 4 was a circumstantial evidence for validity of the assumption on incubation period.

The ASM-estimated airborne spore catches $\left(\hat{S}_{i}\right)$ was only one independent variable that was highly significant in IRM. During the period from the next day after the end of rainfall till the appearance of disease symptoms, none of the 13 weather factors were found to be significant in explaining the variation of $R_{i}$ in 2013. This result suggested that weather conditions during incubation period in JuneOctober of Korea might not have apparent influence on changes in the rate of disease increase. Instead, moist conditions during infection period may cause different levels of disease incidence. Lee et al. (2011) found that moist treatments $\left(100 \%\right.$ relative humidity at $\left.20^{\circ} \mathrm{C}\right)$ for 1,2 , and 3 days immediately after spray inoculation to 4-year old potted apple plants resulted in disease severity of $0,20.3$, and $72.5 \%$, respectively, after $40-45$ days in the field. In this study, we defined the SLP to be the days of a rain event plus the following 2 days after the end of rain event. During SLP, major portions of airborne conidia were released from inoculum sources as shown in Figs. 3 and 4 , and fungal infections by airborne conidia must have occurred as well.

The results from paired $t$-test and Shapiro-Wilk test suggest that ASM is capable of predicting airborne spore catches during SLP of a rain event, whereas IRM is not able to predict daily infection rate at 21 days after a rain event. However, the coefficient of determination $\left(R^{2}=0.788\right)$ of IRM indicates usefulness of the ASMestimated airborne spore catches $\left(\hat{S}_{i}\right)$ as an indicator for possible development of the disease in 3 weeks later, if a threshold of $\hat{S}_{i}$ for successful infection is determined. With an appropriate threshold of $\hat{S}_{i}$, ASM alone can be useful in determining whether or not to spray fungicides after rainfall to control MBA in orchards. If ASM is used for disease warnings based on observed weather data, curative fungicides need to be sprayed because the pathogen must have made infection during the period of rainy days and the following 2 days after the end of rain event.

In conclusion, it was found in this study that three rainrelated weather variables such as of $L_{d a y}$ and $P_{\max }$ and $W_{\text {avg }}$ affected the amount of airborne spores of $M$. coronaria, and the airborne spore amount appeared the main factor affecting daily infection rate of the fungus. No weather variables during the incubation period showed significance in explaining variations of the daily infection rate. The MBCAST, which consists of ASM and IRM, needs to be improved in order to be used practically in a decisionmaking support system for management of Marssonina blotch of apple. Further studies are necessary to determine a threshold of airborne spore catches for successful infections and identify pivotal environmental variables affecting infection rate of the disease.

\section{Acknowledgments}

This work was funded by the Korea Meteorological Administration Research and Development Program under Grant KMI2018-04511.

\section{References}

Allen, M. P. 1997. Understanding regression analysis. Plenum Press, New York, NY, USA. 216 pp.

Anil, K. and Sharma, J. N. 2013. Effect of abiotic factors on Marssonina blotch causing premature leaf fall in apple (Malus domestica). Indian Phytopathol. 66:278-283.

Aylor, D. E. 1975. Force required to detach conidia of Helminthosporium maydis. Plant Physiol. 55:99-101.

Aylor, D. E., McCartney, H. A. and Bainbrioge, A. 1981. Deposition of particles liberated in gusts of wind. J. Appl. Meteorol. Clim. 20:1212-1221.

Back, C.-K. and Jung, H.-Y. 2014. Biological characterization of Marssonina coronaria infecting apple trees in Korea. Korean J. Mycol. 42:183-190 (in Korean).

Burch, M. and Levetin, E. 2002. Effects of meteorological conditions on spore plumes. Int. J. Biometeorol. 46:107-117.

Davis, J. M. 1987. Modeling the long-range transport of plant pathogens in the atmosphere. Annu. Rev. Phytopathol. 25:169-188.

Do, Y. S. and Park, M. Y. 2015. Development of integrated management technic for control of apple brown leaf spot. Rural Development Administration, Jeonju, Korea. 44 pp.

Fitt, B. D. L., McCartney, H. A. and Walklate, P. J. 1989. The role of rain in dispersal of pathogen inoculum. Annu. Rev. Phytopathol. 27:241-270.

Gottwald, T. R. and Bertrand, P. F. 1982. Patterns of diurnal and 
seasonal airborne spore concentrations of Fusicladium effusum and its impact on a pecan scab epidemic. Phytopathology 72:330-335.

Hammett, K. R. W. and Manners, J. G. 1974. Conidium liberation in Erysiphe graminis: III. Wind tunnel studies. Trans. Br. Mycol. Soc. 62:267-282.

Harada, Y., Sawamura, K. and Konno, K. 1974. Diplocarpon mali, sp. nov., the perfect state of apple blotch fungus Marssonina coronaria. Jpn. J. Phytopathol. 40:412-418.

Hirst, J. M. and Stedman, O. J. 1963. Dry liberation of fungus spores by raindrops. J. Gen. Microbiol. 33:335-344.

Kim, C.-H. 2004. Review of disease incidence of major crops in 2003. Res. Plant Dis. 10:1-7 (in Korean).

Kim, D.-A., Lee, S.-W. and Lee, J.-T. 1998. Ecology of marssonina blotch caused by Diplocarpon mali on apple tree in Kyungpook, Korea. Curr. Res. Agric. Life. Sci. 16:84-95 (in Korean).

Kurkela, T. 1997. The number of Cladosporium conidia in the air in different weather conditions. Grana 36:54-61.

Kwak, S. K. and Kim, J. H. 2017. Statistical data preparation: management of missing values and outliers. Korean. J. Anesthesiol. 70:407-411.

Lee, C., Lee, S.-Y., Jung, H.-Y. and Kim, J. 2012. The application of optical coherence tomography in the diagnosis of Marssonina blotch in apple leaves. J. Opt. Soc. Korea 16:133-140.

Lee, D.-H., Back, C.-G., Win, N. K. K., Choi, K.-H., Kim, K.-M., Kang, I.-K., Choi, C., Yoon, T.-M., Uhm, J. Y. and Jung, H.-Y. 2011. Biological characterization of Marssonina coronaria associated with apple blotch disease. Mycobiology 39:200-205.

Lee, D. H., Kim, D. H., Shin, H. C. and Uhm, J. Y. 2008. Development of a 15-day interval spraying program for controlling major apple diseases. Plant Pathol. J. 24:439-446.

Lee, D. H., Lee, S. W., Choi, K. H., Kim, D. A. and Uhm, J. Y. 2006. Survey on the occurrence of apple diseases in Korea from 1992 to 2000. Plant Pathol. J. 22:375-380.

Lee, D. H., Shin, H. C., Cho, R. H. and Uhm, J. Y. 2009. Reducing fungicidal spray frequency for major apple diseases by increasing the spray interval from 15 to 25 days. Plant Pathol. J. 25:270-279.

Lee, Y. H., Cho, W. D., Kim, W. K., Lee, E. J., Han, S. J. and Chung, H. S. 1993. Detailed survey of apple and pear diseases in major fruit producing areas of Korea ('88 '92). Korean J. Plant Pathol. 9:47-51.

Legg, B. J. and Powell, F. A. 1979. Spore dispersal in a barley crop: a mathematical model. Agric. Meteorol. 20:47-67.

Li, J., Gou, L.-X., Hu, X.-M., Ren, F.-P., Wei, J.-F. and An, D.R. 2011. Effects of climate factors on the epidemic of apple Marssonina blotch in Shaanxi Province and related prediction models. Chin. J. Appl. Ecol. 22:268-272 (in Chinese).

Magarey, R. D., Sutton, T. B. and Thayer, C. L. 2005. A simple generic infection model for foliar fungal plant pathogens. Phytopathology 95:92-100.

McCartney, H. A. 1994. Dispersal of spores and pollen from crops. Grana 33:76-80.

McCartney, H. A. and Bainbridge, A. 1984. Deposition gradients near to a point source in a barley crop. J. Phytopathol. 109:219-236.

Oliveira, M., Ribeiro, H., Delgado, J. L. and Abreu, I. 2009. The effects of meteorological factors on airborne fungal spore concentration in two areas differing in urbanisation level. Int. J. Biometeorol. 53:61-73.

Park, M.-Y., Sagong, D.-H., Kweon, H.-J., Do, Y.-S., Song, Y.Y. and Lee, D.-H. 2013. Influence of seasonal incidence and defoliation degree of Marssonina blotch on fruit quality and shoot growth of 'Fuji'/M.9 apple tree. Korean J. Hortic. Sci. Technol. 31:523-530 (in Korean).

Penet, L., Guyader, S., Pétro, D., Salles, M. and Bussière, F. 2014. Direct splash dispersal prevails over indirect and subsequent spread during rains in Colletotrichum gloeosporioides infecting yams. PLoS ONE 9:e115757.

Quintero, E., Rivera-Mariani, F. and Bolaños-Rosero, B. 2010. Analysis of environmental factors and their effects on fungal spores in the atmosphere of a tropical urban area (San Juan, Puerto Rico). Aerobiologia 26:113-124.

Sache, I. 2000. Short-distance dispersal of wheat rust spores by wind and rain. Agronomie 20:757-767.

Sagong, D.-H., Kweon, H.-J., Song, Y.-Y., Park, M.-Y., Nam, J.C., Kang, S.-B. and Lee, S.-G. 2011. Influence of defoliation by Marssonina blotch on vegetative growth and fruit quality in 'Fuji'/M.9 apple tree. Korean J. Hortic. Sci. Technol. 29:531-538 (in Korean).

Sastrahidayat, I. R. and Nirwanto, H. 2016. Marssonina leaf blotch on the apple ochard in Batu, Indonesia. Aravita J. Agric. Sci. 38:204-212.

Sharma, J., Sharma, A. and Sharma, P. 2004. Out-break of Marssonina blotch in warmer climates causing premature leaf fall problem of apple and its management. Acta Hortic. 662:405-409.

Sharma, N., Thakur, V. S., Mohan, J., Khurana, S. M. P. and Sharma, S. 2009. Epidemiology of Marssonina blotch (Marssonina coronaria) of apple in India. Indian Phytopathol. 62:348-359.

Takahashi, S., Sawamura, K. and Sato, Y. 1990. Marssonina blotch. In: Compendium of apple and pear diseases, eds. by A. L. Jones and H. S. Aldwinckle, p. 33. American Phytopathological Society, St. Paul, MN, USA.

Tamietti, G. and Matta, A. 2003. First report of leaf blotch caused by Marssonina coronaria on apple in Italy. Plant Dis. $87: 1005$.

Troutt, C. and Levetin, E. 2001. Correlation of spring spore concentrations and meteorological conditions in Tulsa, Oklahoma. Int. J. Biometeorol. 45:64-74.

Uhm, J. Y. 2010. Reduced fungicide spray program for major apple diseases Korea. Agriculture and Horticulture Press, Anyang, Korea. 251 pp.

Van der Plank, J. E. 1963. Plant diseases: epidemics and control. Academic Press, New York, NY, USA. 349 pp.

Willocquet, L., Berud, F., Raoux, L. and Clerjeau, M. 1998. Effects of wind, relative humidity, leaf movement and colony age on dispersal of conidia of Uncinula necator, causal agent of grape powdery mildew. Plant Pathol. 47:234-242. 
Willocquet, L. and Clerjeau, M. 1998. An analysis of the effects of environmental factors on conidial dispersal of Uncinula necator (grape powdery mildew) in vineyards. Plant Pathol. 47:227-233.

Xu, X.-M., Butt, D. J. and Van Santen, G. 1995. A dynamic model simulating infection of apple leaves by Venturia inaequalis.
Plant Pathol. 44:865-876.

Zhao, H., Huang, L., Xiao, C. L., Liu, J., Wei, J. and Gao, X. 2010. Influence of culture media and environmental factors on mycelial growth and conidial production of Diplocarpon mali. Lett. Appl. Microbiol. 50:639-644. 